\title{
Evaluation of Stress State in a Brick Lining of a Hot Rotary Kiln due to Material and Design Change
}

\author{
Dmitrij Ramanenka ${ }^{1}$, Gustaf Gustafsson ${ }^{1}$, Pär Jonsén ${ }^{1}$, Lars-Olof Nordin ${ }^{2}$ \\ ${ }^{1}$ Luleå University of Technology \\ 971 87, Luleå, Sweden \\ dmitrij.ramanenka@1tu.se; gustaf.gustafsson@1tu.se; par.jonsen@1tu.se \\ ${ }^{2}$ Loussavaara-Kiirunavaara Limited \\ 972 33, Luleå, Sweden \\ lars-olof.nordin@lkab.com
}

\section{Extended Abstract}

Rotary kilns are important in a variety of manufacturing areas, where production of cement clinkers, iron-ore pellets and lime are some of the products. A rotary kiln simply consists of a cylindrical steel casing lined with refractories in order to protect the casing from high temperatures. The dimensions of a rotary kiln vary between some 10 to $180 \mathrm{~m}$ in length and 2 to $8 \mathrm{~m}$ in diameter. Damage of the refractory lining is common and can potentially lead to production shut-downs and high production losses. Due to the harsh inner environment and the large dimensions of the kiln it is difficult to observe and evaluate the kiln while in service - hindering the improvements of the kiln. Therefore, it is advantageous to perform computer simulations and potentially improve the design, the material choice and operation of the kiln based on the numerical results.

A finite element model (FEM) of a rotary kiln was previously created for studying stress state of the brick lining under various conditions, see [1] and [2]. In this work the model will be used for the evaluation of stress state of the lining due to material and design change of the lining. The lining will be studied in hot condition during time-dependent events, such as heating of the kiln. Preliminary results show that stresses in the lining are much higher during heating of the kiln compared to steady state conditions. Conservative change $(<10 \%)$ of brick thickness has insignificant influence on the stress levels in the brick lining. Chang of material parameters, such as elastic modulus and thermal expansion coefficient, leads in general to a proportional increase or decrease of stresses in the brick lining.

The purpose of this study is to investigate if it is possible to suggest an improved design and material choice based on the conducted thermo-mechanical evaluation. The commercial FE-software, LS-DYNA, is used for the numerical simulations of the kiln and the standalone package, LS-OPT, for the calibration of the heat transfer coefficients.

\section{References}

[1] D. Ramanenka, J. Stjernberg and P. Jonsén, "FEM investigation of global mechanisms affecting brick lining stability in a rotary kiln in cold state," Eng. Fail. Anal., vol. 59, pp. 554-569, 2016.

[2] D. Ramanenka, M-L. Antti, G. Gustafsson and P. Jonsén, "Characterization of high-alumina refractory bricks and modelling of hot rotary kiln behaviour," Eng. Fail. Anal., 2017. 